\title{
Comparison of different mathematical functions for fitting growth curves of ascitic and healthy broiler chickens
}

\author{
Ramin NEMATZADEH ${ }^{1, \mathrm{a}}$, Sadegh ALIJANI ${ }^{1, \mathrm{~b}, \varpi}$, Karim HASANPUR $^{1, \mathrm{c}}$, Majid OLYAYEE $^{1, \mathrm{~d}}$, \\ Jalil SHODJA $^{1, \mathrm{e}}$ \\ ${ }^{1}$ University of Tabriz, Faculty of Agriculture, Department of Animal Science, Tabriz, Iran. \\ aORCID: 0000-0003-0413-5132; ' 'ORCID: 0000-0001-5839-2164; 'ORCID: 0000-0001-8936-684X; \\ ${ }^{\mathrm{d} O R C I D: 0000-0002-8764-2895 ;}{ }^{\mathrm{e} O R C I D: 0000-0001-6312-2695}$ \\ Corresponding author: sad-ali@tabrizu.ac.ir \\ Received date: 18.12.2020 - Accepted date: 11.08.2021
}

\begin{abstract}
Ascites syndrome (AS) causes major economic losses in commercial meat-type chickens. The objectives of the current study were to select the best non-linear growth curve functions (GCFs) of the ascitic and healthy chickens, and to investigate the association of ascites incidence with the growth pattern. A total of 5584 body weight (BW) records belonging to 823 chickens ( 381 male and 442 female) from a paternal pure Arian broiler line were used. The birds were categorized into; healthy male and female, ascitic male and female. Five GCFs including Logistic, Gompertz, Lopez, Richards, and Von baretanalffy were fitted to the BW records of all groups, separately. After the estimation of growth curve parameters for all the chicks individually, the effect of sex and health status on the growth curve parameters were assessed. The results revealed that the Richards function is the best for all the groups. Comparison of the growth curves showed that the ascitic chickens reach the inflection point of the curve earlier than their healthy counterparts $(\mathrm{P}<0.05)$. The average growth rate of the healthy birds in the rearing period was significantly higher than that of the ascitic birds $(\mathrm{P}<0.05)$, thereby suggesting that there is no direct relationship between the rapid growth rate and the incidence of ascites. Therefore, genetic improvement of the used population for both rapid growth rate and reduced ascites incidence may be possible and the utilization of growth curve parameters in the selection index might be beneficial.
\end{abstract}

Keywords: Ascites, broiler, growth pattern, non-linear functions.

\section{Introduction}

Ascites syndrome (AS) (also called pulmonary hypertension syndrome) is a metabolic disorder in modern meat-type chickens that are associated with pathological accumulation of excessive fluid in the abdominal cavity. AS is affected by both environmental and genetic factors $(4,9)$. The incidence of AS in commercial meat-type chickens is more prevalent and the range of mortality can rate from 0 to $30 \%$, therefore, AS could result in massive economic losses to poultry producers $(15,16)$. There is a direct association between the local elevation of broiler houses (sea level above $3500 \mathrm{~m}$ ) and the prevalence of AS, so that it has historically been called high altitude disease $(5,10)$. However, it is now widely seen even at low altitude areas, as well (6). In such a condition, the incidence of AS is attributed to the rapid growth rate, especially in male chickens (18). The growth rate of broiler chicken is higher at early ages and the slope of the growth curve is steeper as compared to later ages. The growth rate subsequently decreases progressively to finally reach zero at maturity (8). The growth rate of ascitic birds is much slower than that of healthy ones and their final weight is lighter at the end of the rearing period (4). Nowadays, the growth curve has various applications and could be used in the optimization of management practices, evaluation of nutritional requirements, and improvement of breeding programs (1). Growth curves functions (GCFs) are nonlinear regression equations that predict body weight (BW) at different stages of animal life $(12,14)$. Understanding the biological meanings of the growth curve parameters and their relationship with other important economic traits may pave the way for experts to use this information in breeding plans (23). To this end, the study of the growth curves of the birds is necessary for the breeder to genetically evaluate the birds (2). Besides, the growth curves can be used as an appropriate tool by breeders to make important decisions about the nutritional and management strategies of farms $(1,2,12,26)$. The GCFs that are used more commonly are Gompertz, Richards, Von Bertalanffy, Brody, Logistic, Negative 
Exponential, Morgan - Mercer - Flodin, and recently the Hyperbolastic models $(12,14,25)$. These GCFs have been developed to model both the unprecedented and intraspecific population dynamics and more general biological growth. Most predictive models are based on variations of Verhulst's classic logistic growth equation (25). The Gompertz function, which was first presented for the prediction of animal growth, is one of the best models to describe the growth patterns of birds $(3,13,21)$. The parameters of the Gompertz function are flexible, however, the Richards model has variable flexibility (19). The intense genetic selection of modern meat-type broilers for fast growth rate, high marketing weight, maximum white meat yield, and heavy final BW has augmented the incidence of $\mathrm{AS}(5,15,16)$. It seems that internal organs of modern broiler chickens such as heart, lungs, and liver, especially those with AS characteristics, are not well developed as compared with those of healthy birds or layer hens $(6,8,18)$. Because of the inherent differences between the growth patterns of the healthy and ascitic birds (8), we aimed to select the best non-linear GCFs including Gompertz, Logistic, Lopez, Richards, and Von Bertalanffy in the fitting of the growth curves of four groups including healthy male, healthy female, ascitic male, and ascitic female and to investigate the association of ascites incidence with the growth pattern.

\section{Materials and Methods}

In this research, we examined different GCFs and the incidence of ascites under standard rearing conditions using 5584 body weight records of 823 chicks belonging to one paternal commercial broiler line of Arian. All birds were wing-banded at the hatchery for pedigree registration. Then, Chicks were immediately transformed to the Poultry Research Unit, located in Khalatposhan Agricultural Research Station of University of Tabriz, Tabriz, Iran and were raised on the deep floor according to Arian management guidelines to $45 \mathrm{~d}$ of age. The lighting schedule was near-continuous lighting (23L: 1D) throughout the experimental periods. The broiler chickens were housed in pens in a litter floor and reared under similar managerial and hygienic conditions. The temperature of rearing room was controlled at $32^{\circ} \mathrm{C}$ for first $3 \mathrm{~d}$, then decreased gradually to $20^{\circ} \mathrm{C}$ until $21 \mathrm{~d}$ of age and maintained as such until $42 \mathrm{~d}$. The water and feed were supplied ad libitum throughout the experimental period. The water was supplied by a bell-shaped drinker, and feed was provided to each pen by a plate feeder to 10 days of age and then by an $8 \mathrm{~kg}$ grower feeder from 10 to 45 days of age. The metabolizable energy $(\mathrm{kcal} / \mathrm{kg})$ and crude protein $(\%)$ contents of the starter ( 1 to $14 \mathrm{~d})$, grower (15 to $28 \mathrm{~d}$ ), and finisher (29 to $45 \mathrm{~d}$ ) diets were $2900 \mathrm{kcal} / \mathrm{kg}$ and $20.5 \%, 3075 \mathrm{kcal} / \mathrm{kg}$ and $20 \%$, and $3120 \mathrm{kcal} / \mathrm{kg}$ and $18 \%$, respectively. The ingredients and chemical composition of the basal diets were listed in Table 1 . The

Table 1. The ingredients and nutrient composition of the basal diet (\%, as-fed bases).

\begin{tabular}{|c|c|c|c|}
\hline Ingredients (\%) & Starter, d 0-10 & Grower, d 11-24 & Finisher, d 25- 42 \\
\hline Yellow corn & 62.10 & 69.00 & 71.73 \\
\hline Soybean meal (440 g/kg CP) & 34.10 & 28.30 & 25.70 \\
\hline Wheat bran & 0.98 & - & - \\
\hline Dicalcium phosphate & 0.20 & 0.20 & 0.19 \\
\hline $\mathrm{CaCO}_{3}$ & 1.10 & 1.00 & 0.95 \\
\hline DL-Methionine & 0.33 & 0.29 & 0.26 \\
\hline L- Lysine & 0.22 & 0.20 & 0.17 \\
\hline 1- Threonine & 0.08 & 0.07 & 0.07 \\
\hline $\mathrm{NaCl}$ & 0.22 & 0.24 & 0.23 \\
\hline $\mathrm{NaCO}_{3}$ & 0.17 & 0.15 & 0.15 \\
\hline Vitamin premix ${ }^{1}$ & 0.25 & 0.25 & 0.25 \\
\hline Mineral premix $^{2}$ & 0.25 & 0.25 & 0.25 \\
\hline Coccidiostat & - & 0.05 & 0.05 \\
\hline Total & 100 & 100 & 100 \\
\hline \multicolumn{4}{|l|}{ Analyzed nutrient levels } \\
\hline Metabolizable energy, $\mathrm{kcal} / \mathrm{kg}$ & 2900 & 3075 & 3120 \\
\hline Crude protein $(\mathrm{CP}), \%$ & 20.50 & 20.00 & 18.00 \\
\hline Ether exact, $\%$ & 3.37 & 3.35 & 3.29 \\
\hline Calcium, $\%$ & 1.00 & 0.95 & 0.95 \\
\hline Available phosphorus, $g / k$ & 0.45 & 0.43 & 0.43 \\
\hline Lysine, $\mathrm{g} / \mathrm{kg}$ & 1.17 & 1.10 & 1.08 \\
\hline Methionine, $\mathrm{g} / \mathrm{kg}$ & 0.55 & 0.51 & 0.45 \\
\hline
\end{tabular}

${ }^{1}$ Provided per kilogram of diet: vitamin A, $8000 \mathrm{IU}$; vitamin D3, $1600 \mathrm{IU}$; vitamin E, $10 \mathrm{IU}$; vitamin B1, $0.8 \mathrm{mg}$; vitamin B2, $2.5 \mathrm{mg}$; vitamin B6, $0.1 \mathrm{mg}$; vitamin B12, $0.009 \mathrm{mg}$; D-pantothenic acid, $2.2 \mathrm{mg}$, folic acid $0.25 \mathrm{mg}$; nicotinic acid $20 \mathrm{mg}$; biotin $0.1 \mathrm{mg}$.

${ }_{2}^{2}$ Provided per kilogram of diet: $6 \mathrm{mg}\left(\mathrm{MnO}_{2}\right) ; 80 \mathrm{mg}\left(\mathrm{ZnSO}_{4} \cdot 7 \mathrm{H}_{2} \mathrm{O}\right) ; 8 \mathrm{mg}\left(\mathrm{CuSO}_{4} \cdot 5 \mathrm{H}_{2} \mathrm{O}\right) ; 60 \mathrm{mg}\left(\mathrm{FeSO}_{4} \cdot 7 \mathrm{H}_{2} \mathrm{O}\right) ; 0.35 \mathrm{mg}(\mathrm{KI})$ and $0.3 \mathrm{mg}\left(\mathrm{Na}_{2} \mathrm{SeO}_{3} \cdot 5 \mathrm{H}_{2} \mathrm{O}\right)$. 
body weights of the chicks were individually taken with a precision digital scale sensitive to $\pm 0.01 \mathrm{~g}$ by weekly and the dead birds were necropsied for determination of the cause of death. All birds with yellow fluid at the peritoneal cavity or in pericardium were considered as ascitic, while the remaining birds were considered as healthy. After the end of the rearing period, the birds were divided into four groups including healthy male $(\mathrm{n}=317)$, ascitic male $(n=64)$, healthy female $(n=424)$, and ascitic female $(n=18)$. The sex determination was done by gender appearance differences. In this method, male broilers have a larger body size, comb, and wattle in comparison with female broiler chicks.

The effects of sex and health status on BW at different ages were studied using the GLMSELECT procedure of SAS software version 9.2 (22) and found to be significant $(\mathrm{P}<0.05)$ on weekly recorded $\mathrm{BW}$ (results not shown). For this reason, the fitting of the different GCFs was done separately for ascitic males, ascitic females, healthy males, and healthy females, using the nonlinear (NLIN) procedure of SAS software (22). Consequently, in the first step five nonlinear models including Gompertz (G), Logistic (L), Lopez (Lo), Richards (R), and Von Bertalanffy (VB) were employed to fit the average weekly weighed BW records. The mathematical equations of the functions are shown in Table 2.

Table 2. Growth curve functions used to fit bodyweight records.

\begin{tabular}{ll}
\hline Model & Function* \\
\hline Gompertz & $\mathrm{Wt}=\mathrm{W} 0 \times \exp ((1-\exp (-\mathrm{b} \times \mathrm{t})) \times(\log (\mathrm{Wf} / \mathrm{W} 0)))$ \\
Logistic & $\mathrm{Wt}=(\mathrm{W} 0 \times \mathrm{Wf}) /(\mathrm{W} 0+(\mathrm{Wf}-\mathrm{W} 0) \times \exp (-\mathrm{b} \times \mathrm{t}))$ \\
Lopez & $\mathrm{Wt}=\left(\left(\mathrm{W} 0 \times k^{b}\right)+\left(\mathrm{Wf} \times t^{b}\right)\right) /\left(k^{b}+t^{b}\right)$ \\
Richard & $\mathrm{Wt}=\left(\mathrm{W}_{0} \times \mathrm{W}_{\mathrm{f}}\right) /\left(\left(\mathrm{W}_{0}^{\mathrm{n}}\right)+\left(\mathrm{W}_{\mathrm{f}}^{\mathrm{n}}-\mathrm{W}_{0}^{\mathrm{n}}\right) \times \exp (-\mathrm{b} \times \mathrm{t})\right)(1 / \mathrm{n})$ \\
$\begin{array}{l}\text { Von } \\
\text { Bertalanffy }\end{array}$ & $\mathrm{W}_{\mathrm{t}}=\mathrm{a} \times(1-\mathrm{b} \times \exp (-\mathrm{k} \times \mathrm{t}))^{3}$ \\
\hline
\end{tabular}

* Wt is the body weight (g) at age $\mathrm{t}$ (day), W0 is the initial weight, Wf is body weight at maturity, $\mathrm{b}$ the maturity index, $\mathrm{k}$ and $\mathrm{n}$ are the parameters of the functions.

The adjusted coefficient of determination $\left(\operatorname{Adj}-\mathrm{R}^{2}\right)$, Akaike information criterion $\left(\mathrm{AIC}_{\mathrm{c}}\right)$, and Durbin-Watson (DW) criteria were used to assess the goodness of fits of the functions. The calculation formula of these criteria were as follow:

1- $\operatorname{Adj}-R^{2}$ statistic:

$$
\operatorname{Adj}-R^{2}=1-\frac{(\mathrm{n}-1)}{(\mathrm{n}-\mathrm{p})} \times\left(1-\mathrm{R}^{2}\right)
$$

In which, $\mathrm{R}^{2}$ is the explanation factor, $\mathrm{n}$ is the number of observations, and $\mathrm{p}$ is the number of parameters of the model.

\section{2- AICc statistic:}

$\mathrm{AICc}=\mathrm{n} \log (\mathrm{RSS} / \mathrm{n})+2 \mathrm{p}(\mathrm{n} /(\mathrm{n}-\mathrm{p}-1))$

In which, SSR is the sum of squares corresponds to the models, and $\mathrm{n}$ and $\mathrm{p}$ are the number of observations and the number of parameters of the model, respectively.

3- Durbin-Watson (DW) statistic:

$$
\mathrm{DW}=\frac{\sum_{\mathrm{t}=2}^{\mathrm{n}}\left(\mathrm{e}_{\mathrm{t}}-\mathrm{e}_{\mathrm{t}-1}\right)^{2}}{\sum_{\mathrm{t}=1}^{\mathrm{n}} \mathrm{e}_{\mathrm{t}}^{2}}
$$

In which, $e_{t}$ and $e_{t-1}$ are the residual values at days $t$ and $\mathrm{t}-1$.

Comparison of the different goodness of fit criteria proved that the Richards function as the best for all of the groups and, therefore, in the second step this model was employed to fit the individual $\mathrm{BW}$ records of the birds.

After estimating the parameters of the Richards function for individual birds, the parameters were used to calculate the time $\left(\mathrm{T}_{\mathrm{IP}}\right)$ and weight $\left(\mathrm{W}_{\mathrm{IP}}\right)$, at the inflection point of the growth curve (as $\mathrm{T}_{\mathrm{IP}}$ and $\mathrm{W}_{\mathrm{IP}}$, respectively) as below:

$$
\begin{gathered}
\mathrm{T}_{\mathrm{IP}}=\frac{1}{\mathrm{~b}} \ln \left[\frac{\mathrm{W}_{\mathrm{f}}-\mathrm{W}_{0}}{n \mathrm{~W}_{\mathrm{f}}}\right] \\
\mathrm{W}_{\mathrm{IP}}=\frac{\mathrm{W}_{\mathrm{f}}}{(\mathrm{n}+1)^{1 / \mathrm{n}}}
\end{gathered}
$$

Then, the GLM procedure of SAS software was used to assess the effect of sex and health status (healthy or ascites) on the growth curve parameters, using the following model:

$$
\mathrm{y}_{\mathrm{ijk}}=\mu+\mathrm{S}_{\mathrm{i}}+\mathrm{HS}_{\mathrm{j}}+\mathrm{e}_{\mathrm{ijk}}
$$

In which, $y_{\mathrm{ijk}}$ is any parameters of Richards function, $\mu$ is overall mean, $S_{i}$ and $H S_{j}$ are the fixed effects of sex and health status (healthy or ascitic), respectively, and $\mathrm{e}_{\mathrm{ijk}}$ is the random residual.

At last, the correlation coefficients between the growth curve parameters were estimated using the CORR procedure of SAS software (22).

\section{Results}

Descriptive statistics and selection of the best growth model: Table 3 describes the descriptive statistics of the used data. The growth curves of the four groups were fitted using all of the studied functions and the resulted curves are shown in Figure 1 (labelled as A, B, C, D and E). As can be seen in Figure 1, before the age of 28 days, all groups had almost similar growth patterns, with the ascitic birds being slightly heavier than their healthy counterparts. After the age of 28 days, the growth rate of all groups diminished gradually. But, the reduction of growth rate was more considerable for the ascitic male and ascitic female groups than their corresponding healthy groups.

The goodness of fit of the GCFs was assessed using Adj-R ${ }^{2}$, AIC $_{C}$, DW statistics, and the results are shown in Table 4. Function with the highest $\mathrm{Adj}-\mathrm{R}^{2}$, the lowest $\mathrm{AIC}_{\mathrm{C}}$, and DW around 2 was considered as the most suitable. 


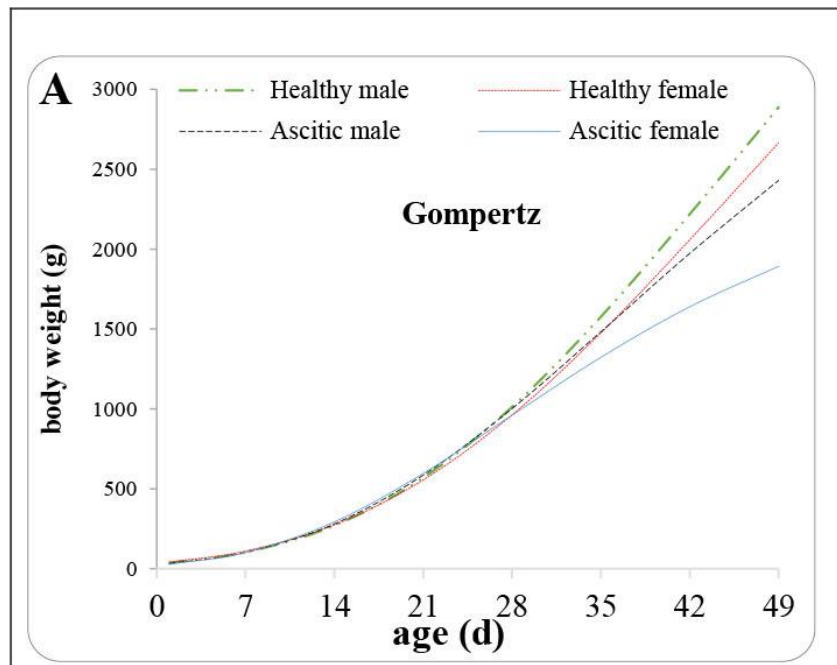

A: Fitting growth curve of the Gompertz model for healthy and ascitic male and female broiler chickens.

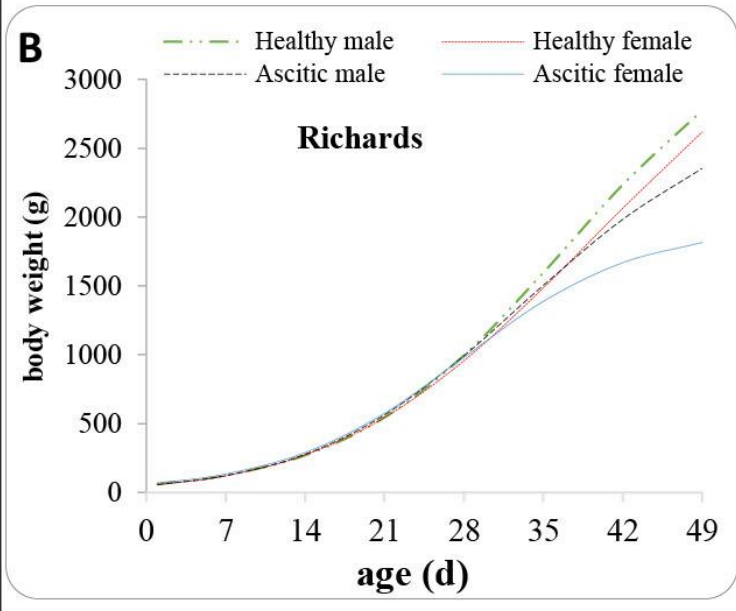

B: Fitting growth curve of the Richards model for healthy and ascetic male and female broiler chickens.

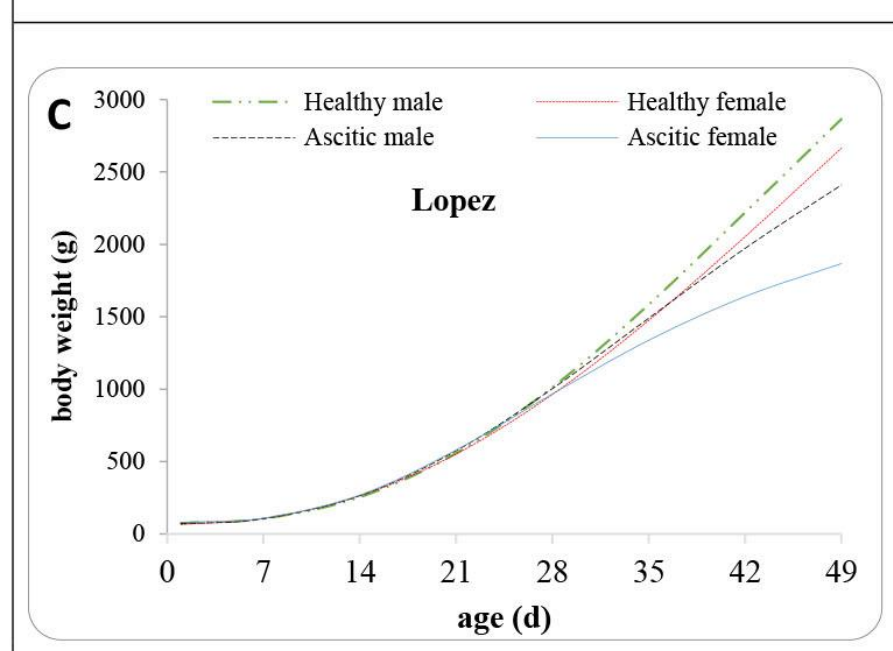

C: Fitting growth curve of the Lopez model for healthy and ascetic male and female broiler chickens.

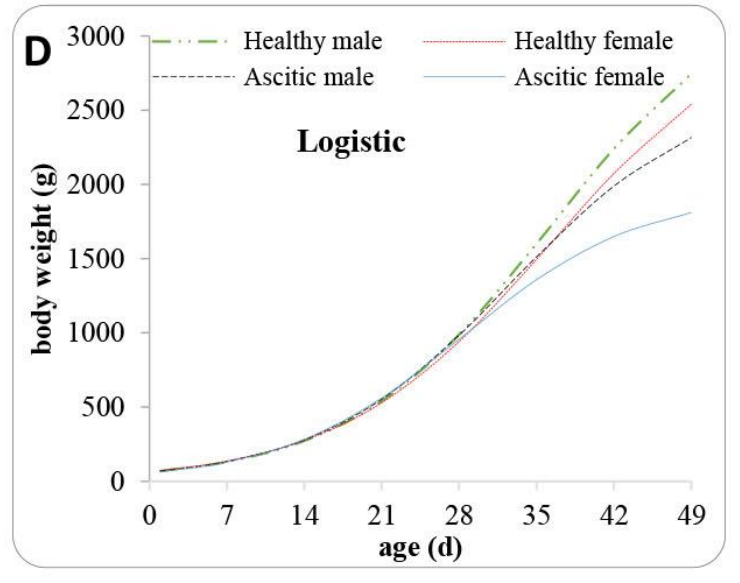

D: Fitting growth curve of the Logistic model for healthy and ascetic male and female broiler chickens.

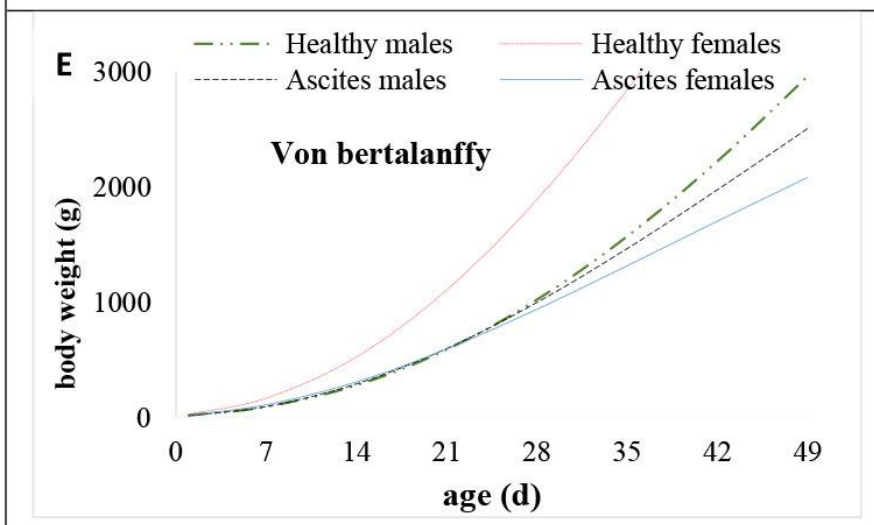

E: Fitting growth curve of the Von Bertalanffy model for healthy and ascetic male and female broiler chickens.

Figure 1. Fitting five different growth curves for healthy and ascitic male and female broiler chickens. 
Table 3. Descriptive statistics of used BW records in different ages.

\begin{tabular}{cccccc}
\hline Age $($ Day $)$ & Mean $(\mathbf{g})$ & SD $^{\mathbf{1}}(\mathbf{g})$ & $\mathbf{C V}^{\mathbf{2}}(\boldsymbol{\%})$ & Minimum $(\mathbf{g})$ & Maximum $(\mathbf{g})$ \\
\hline 1 & 45 & 3.9 & 8.8 & 33 & 60 \\
7 & 127 & 75.1 & 14.6 & 68 & 184 \\
14 & 274 & 53.4 & 19.4 & 104 & 443 \\
21 & 574 & 98.7 & 17.1 & 230 & 885 \\
28 & 972 & 164.1 & 16.8 & 420 & 1485 \\
35 & 1519 & 242.8 & 15.9 & 470 & 2200 \\
42 & 2133 & 301.7 & 14.1 & 1070 & 3025 \\
45 & 2363 & 338.4 & 14.3 & 1205 & 4425 \\
\hline
\end{tabular}

${ }^{1} \mathrm{SD}$ : standard deviation, ${ }^{2} \mathrm{CV}$ : coefficient of variance.

Table 4. The goodness of fit criteria of Richards, Lopez, Logistic, Gompertz and Von Bertalanffy functions for fitting the growth curves of healthy and ascitic male and female birds.

\begin{tabular}{|c|c|c|c|c|c|c|c|c|c|c|c|c|c|c|c|}
\hline Criteria & & & $\mathbf{R}^{2}{ }_{\text {adj }}{ }^{1}$ & & & & & $\mathbf{A I C}_{\mathbf{C}}$ & & & & & DW $^{3}$ & & \\
\hline $\begin{array}{c}\text { Function* } \\
\text { Group }\end{array}$ & $\mathbf{G}$ & $\mathbf{L}$ & Lo & $\mathbf{R}$ & VB & $\mathbf{G}$ & $\mathbf{L}$ & Lo & $\mathbf{R}$ & VB & $\mathbf{G}$ & $\mathbf{L}$ & Lo & $\mathbf{R}$ & VB \\
\hline $\begin{array}{l}\text { Healthy } \\
\text { males }\end{array}$ & 0.998 & 0.975 & 0.998 & 0.999 & 0.998 & 78.2 & 68.62 & 78.9 & 67.8 & 83.94 & 2.04 & 2.07 & 2.15 & 2.51 & 1.69 \\
\hline $\begin{array}{l}\text { Healthy } \\
\text { females }\end{array}$ & 0.997 & 0.995 & 0.994 & 1 & 0.999 & 65.5 & 70.42 & 70.6 & 54.2 & 76.14 & 1.82 & 1.22 & 2.12 & 2.38 & 1.46 \\
\hline $\begin{array}{l}\text { Ascites } \\
\text { males }\end{array}$ & 0.998 & 0.995 & 0.997 & 0.999 & 0.998 & 76.6 & 69.57 & 76.4 & 66.2 & 83.28 & 1.91 & 2.37 & 2.28 & 3.07 & 1.58 \\
\hline $\begin{array}{l}\text { Ascites } \\
\text { females }\end{array}$ & 0.995 & 0.997 & 0.995 & 0.999 & 0.995 & 85.4 & 78.34 & 84.3 & 78.2 & 89.10 & 1.97 & 2.83 & 2.30 & 2.85 & 1.72 \\
\hline
\end{tabular}

*G: Gompertz, L: Logistic, Lo: Lopez, R: Richards, and VB: Von Bertalanffy.

${ }^{1}$ adjusted coefficient of determination, ${ }^{2}$ Akaike information criterion, ${ }^{3}$ Durbin-Watson criteria.

Table 5. Least square means (LSM) comparison of growth curve parameters among different groups of gender and health status.

\begin{tabular}{ccccc}
\hline & Healthy male & Ascitic male & Healthy female & Ascitic female \\
\hline $\mathrm{W}_{0}$ & $55.7^{\mathrm{a}}$ & $56.5^{\mathrm{a}}$ & $47.9^{\mathrm{b}}$ & $63.9^{\mathrm{a}}$ \\
$\mathrm{W}_{\mathrm{f}}$ & $3967^{\mathrm{b}}$ & $2877^{\mathrm{c}}$ & $5001^{\mathrm{a}}$ & $2112^{\mathrm{c}}$ \\
$\mathrm{b}$ & $0.219^{\mathrm{b}}$ & $0.666^{\mathrm{a}}$ & $0.118^{\mathrm{b}}$ & $0.414^{\mathrm{ab}}$ \\
$\mathrm{n}$ & $2.34^{\mathrm{b}}$ & $7.01^{\mathrm{a}}$ & $1.06^{\mathrm{b}}$ & $4.08^{\mathrm{ab}}$ \\
$\mathrm{W}_{\mathrm{IP}}$ & $1862^{\mathrm{b}}$ & $1457^{\mathrm{c}}$ & $2043^{\mathrm{a}}$ & $1158^{\mathrm{c}}$ \\
$\mathrm{T}_{\mathrm{IP}}$ & $37.3^{\mathrm{b}}$ & $33.4^{\mathrm{c}}$ & $40.6^{\mathrm{a}}$ & $29.7^{\mathrm{c}}$ \\
\hline
\end{tabular}

$\mathrm{W}_{0}$ is the hatching weight, $\mathrm{W}_{\mathrm{f}}$ is the weight at maturity, $\mathrm{b}$ the maturity index, $\mathrm{n}$ is the parameters of the model, $\mathrm{W}_{\mathrm{IP}}$ and $\mathrm{T}_{\mathrm{IP}}$ are weight- and age at the inflection point of the growth curve, respectively.

LSM within the same row with different superscripts are significantly different $(\mathrm{P}<0.05)$.

Table 6. Correlation between the growth curve parameters in healthy (above diagonal) and ascitic chickens (below diagonal).

\begin{tabular}{ccccccc}
\hline Parameters $^{*}$ & $\mathbf{W}_{\mathbf{0}}$ & $\mathbf{W}_{\mathbf{f}}$ & $\mathbf{b}$ & $\mathbf{n}$ & $\mathbf{W}_{\text {IP }}$ & $\mathbf{T}_{\text {IP }}$ \\
\hline $\mathrm{W}_{0}$ & - & -0.35 & 0.35 & 0.37 & -0.18 & -0.25 \\
$\mathrm{~W}_{\mathrm{f}}$ & $-0.37^{\mathrm{a}}$ & - & -0.20 & -0.19 & 0.96 & 0.90 \\
$\mathrm{~b}$ & 0.60 & -0.19 & - & 0.99 & -0.10 & -0.07 \\
$\mathrm{n}$ & 0.61 & -0.19 & 0.99 & - & -0.09 & -0.06 \\
$\mathrm{~W}_{\text {IP }}$ & -0.01 & 0.90 & 0.08 & -0.08 & - & 0.92 \\
$\mathrm{~T}_{\text {IP }}$ & -0.25 & 0.89 & -0.10 & -0.09 & 0.85 & - \\
\hline
\end{tabular}

${ }^{*} \mathrm{~W}_{0}$ is the initial weight, $\mathrm{W}_{\mathrm{f}}$ is the maturity, $\mathrm{b}$ the maturity index, $\mathrm{n}$ is the parameters of the model, $\mathrm{W}_{\mathrm{IP}}$ and TIP are weight- and age at the inflection point of the growth curve, respectively.

${ }^{a}$ All correlations are statistically significant $(\mathrm{P}<0.05)$. 
Effect of sex and health status on growth curve parameters: Generally based on the mentioned criteria in table 4, Richards's function was revealed to be the best for all of the four groups which followed by, Logistic, Gompertz, Lopez and VB (based on AIC criterion). Therefore, the Richards function was employed to be fitted to the BW records of all birds, individually. The growth curves of 115 chickens did not reach the convergence criterion or possessed inappropriate shapes and were excluded from further analyses. Therefore, the number of fitted curves reduced to 708 (330 male and 378 female). The growth curve parameters, as well as time and weight at an inflection point of the curve, were estimated for these birds.

In Table 5, the comparison of least-square means of Richards' growth curve parameters among the four groups are shown. There were significant differences between the estimated hatch weight $\left(\mathrm{W}_{0}\right)$ of the four groups $(\mathrm{P}<0.05)$. The mature weights $\left(\mathrm{W}_{\mathrm{f}}\right)$ of the healthy males and healthy females were significantly higher than those of the ascitic males and ascitic females, respectively $(\mathrm{P}<0.05)$. There were significant differences between the $b$ and $n$ parameters of the four groups $(\mathrm{P}<0.05)$. The healthy chickens reached the inflection point of the growth curve later and at a heavier weight than the ascitic chickens $(\mathrm{P}<0.05)$. This indicates that the growth pattern of the ascitic birds is not as similar to that of the healthy birds.

Correlation between the growth curve parameters within the ascitic and healthy chickens: Table 6 shows the correlation coefficients between the growth curve parameters of healthy and ascitic chickens. The correlation coefficients are almost similar in the healthy and ascitic chickens with the highest correlation between $\mathrm{W}_{\mathrm{f}}$ and $\mathrm{W}_{\mathrm{IP}}$ parameters and the lowest correlation between $\mathrm{T}_{\mathrm{IP}}$ and $\mathrm{n}$ parameters.

\section{Discussion and Conclusion}

AS, a serious metabolic disorder in commercial modern broilers, is one of the most important noninfectious causes of losses in the broiler production industry and the incidence of it has increased worldwide over the past several years (7). Meat-type chickens are sensitive to AS due to their genetic improvement history of intense genetic selection for production traits such as rapid growth rate and efficient feed conversion. Furthermore, non-genetic factors are also blamed for predisposing the broilers to AS. These factors are for example high ambient temperature, continuous lighting, improper ventilation, high altitudes, and pellet form of high-energy diets $(4,7,15)$. Many studies have suggested that mortality due to AS could be attributed to metabolic burdening. These conditions have raised great challenges in meat-type chickens during rapid growth for fulfilling tissue demands for oxygen, resulting in relative hypoxemia, with a decrease in arterial oxygen saturation and high hematocrit values with increased red blood cell production (erythropoiesis). Although the pathological progression of AS has been known for years, the underlying molecular mechanism during AS development is still not fully understood (18).

As shown in figure 1, the growth rate of ascitic birds was slightly higher than that of healthy ones before the age of 28 days. Thus, we investigated the possible relationship of early rapid growth rate with the incidence of ascites. We observed no visible, statistical differences between the BW records of healthy and ascites birds before age 28 (results not shown). Therefore, it seems that the slightly faster growth rate of the ascitic birds may not be the causative factor predisposing them to ascites. As such, we should look for other reasons to explain their susceptibility to ascites. The results concluded by Julian (10), was consistent with our results that report the rapid growth of broilers were no the pathogenic mechanism of cardiovascular or musculoskeletal defects. At the end of the rearing period, the $\mathrm{BW}$ of the ascitic chickens was much lower than that of healthy birds which was the case for both males and females. This is inconsistent with the previous findings that considered a positive relationship between the rapid growth rate and the incidence of ascites $(6,9,20)$.

The high correlation of both WIP and TIP with Wf indicates that birds with later inflection point have heavier weight at an inflection point as well as at maturity (Table 6). As mentioned above, healthy chicks have growth curves with later TIP and heavier WIP. Therefore, genetic selection for later TIP can assist in indirectly select for reduced ascites incidence $(13,17,23,24,26)$. Indeed, poultry farmers frequently plan to slower the early growth rate of broiler chickens to postpone the inflection point of the growth curve and to help the chicken to cope with the high metabolic pressure which they experience during the early ages (11). Furthermore, more recently there have been some attempts to develop broiler strains that grow slowly during early ages but grow more rapidly during later ages, something that is so-called compensatory growth $(9,25,27)$.

The birds that suffered from AS showed different and inappropriate growth patterns as compared to the healthy birds. Despite the previous findings, in the studied population, the ascitic birds grew as similar to healthy birds in early ages but at a slower rate at later ages. The inflection point of the growth curve of the ascites birds happened earlier than that of healthy birds indicating that the hindrance of inflection point, via genetically or management strategies, might cause the incidence of ascites to be reduced. 


\section{Acknowledgement}

We cordially appreciated the Arian Farm staff for their technical assists and for providing the pedigreed chickens for the current study.

\section{Ethical Statement}

This study does not present any ethical concerns.

\section{Financial Support}

This research was financially supported by the University of Tabriz grants (project no. 312, Master of Science thesis at University of Tabriz).

\section{Conflict of Interest}

The authors declare no conflicts of interest.

\section{References}

1. Aggrey S (2002): Comparison of three nonlinear and spline regression models for describing chicken growth curves. Poult Sci, 81, 1782-1788.

2. Aggrey S (2009): Logistic nonlinear mixed effects model for estimating growth parameters. Poult Sci, 88, 276-280.

3. Arango J, Van Vleck LD (2002): Size of beef cows: early ideas, new developments. Faculty Papers and Publications in Animal Science, 237.

4. Baghbanzadeh A, Decuypere E (2008): Ascites syndrome in broilers: physiological and nutritional perspectives. Avian Pathol, 37, 117-126.

5. Balog J, Anthony N, Cooper M, et al (2000): Ascites syndrome and related pathologies in feed restricted broilers raised in a hypobaric chamber. Poult Sci, 79, 318-323.

6. Currie RJ (1999): Ascites in poultry: recent investigations. Avian Pathol, 28, 313-326.

7. Gupta A (2011): Ascites syndrome in poultry: a review. Worlds Poult Sci J, 67, 457-468.

8. Hasanpur K, Nassiry M, Salekdeh GH, et al (2015): Influence of ascites syndrome on growth pattern of chickens reared at normal or cold ambient temperature. Ann Anim Sci, 15, 373-385.

9. Hassanzadeh M, Buyse J, Toloei T, et al (2013): Ascites syndrome in broiler chickens: A review on the aspect of endogenous and exogenous factors interactions. J Poult Sci, 51, 229-241.

10. Julian RJ (1993): Ascites in poultry. Avian Pathol, 22, 419454.
11. Kaplan S, Gürcan EK (2018): Comparison of growth curves using non-linear regression function in Japanese quail. J Appl Anim Res, 46, 112-117.

12. Kaufmann KW (1981): Fitting and using growth curves. Oecologia, 49, 293-299.

13. Kuhi HD, Kebreab E, Lopez S, et al (2003): An evaluation of different growth functions for describing the profile of live weight with time (age) in meat and egg strains of chicken. Poult Sci, 82, 1536-1543.

14. Lee L, Atkinson D, Hirst AG, et al (2020): A new framework for growth curve fitting based on the von Bertalanffy Growth Function. Scientific Reports, 10, 1-12.

15. Nurmeiliasari N (2010): Ascites Incidence in Broilers. J Sain Peternak Indones, 5, 59-64.

16. Pavlidis H, Balog J, Stamps L, et al (2007): Divergent selection for ascites incidence in chickens. Poult Sci, 86, 2517-2529.

17. Porter T, Kebreab E, Kuhi HD, et al (2010): Flexible alternatives to the Gompertz equation for describing growth with age in turkey hens. Poult Sci, 89, 371-378.

18. Rabinovitch M (2008): Molecular pathogenesis of pulmonary arterial hypertension. J Clin Invest, 118, 23722379.

19. Richards F (1959): A flexible growth function for empirical use. J Exp Bot, 10, 290-301.

20. Riddell C, Springer R (1985): Cardiomyopathy and ascites in broiler chickens. Proceedings of the $34^{\text {th }}$ Western Poultry Disease Conference, Austria.

21. Sakomura N, Longo F, Oviedo-Rondon E, et al (2005): Modeling energy utilization and growth parameter description for broiler chickens. Poult Sci, 84, 1363-1369.

22. SAS S (2009). STAT user's guide, version 9.2. Cary, NC, USA: SAS Inst, Inc.

23. Segura-Correa J, Santos-Ricalde R, Palma-Avila I (2017): Non-Linear Model to Describe Growth Curves of Commercial Turkey in the Tropics of Mexico. Braz J Poult Sci, 19, 27-32.

24. Şengül T, Kiraz S (2005): Non-linear models for growth curves in Large White turkeys. Turk J Vet Anim Sci, 29, 331-337.

25. Winkel BJ (2012): Sourcing for parameter estimation and study of logistic differential equation. Int J Math Educ Sci Technol, 43, 67-83.

26. Yang Y, Mekki D, Lv S, et al (2006): Analysis of fitting growth models in Jinghai mixed-sex yellow chicken. Int $\mathbf{J}$ Poult Sci, 5, 517-521.

27. Zubair A, Leeson S (1996): Compensatory growth in the broiler chicken: a review. Worlds Poult Sci J, 52, 189-201. 